\title{
Impact of major incidents on health system performance, security and health protection
}

\author{
M. Raich ${ }^{1}$, C. Adler ${ }^{2}$, V. Stühlinger ${ }^{1}$, N. Lorenzoni ${ }^{1} \&$ S. Duschek ${ }^{1}$ \\ ${ }^{1}$ UMIT - Private University of Health Sciences, \\ Medical Informatics and Technology, Austria \\ ${ }^{2}$ LMU - Ludwig-Maximilian-University, Germany
}

\begin{abstract}
Major incidents have direct and indirect consequences for population health and health systems. Direct impacts refer to people who lost their life, to the number of people injured, or to resulting diseases. However, indirect consequences (e.g., losses of living conditions, damages to healthcare systems or affiliated infrastructure) including their impact on population health or health systems are often difficult to assess. The purpose of this study is to identify indirect consequences of five different major incidents in Europe on health system performance, security and health protection with focus on psycho-social support. This study is part of the international multi-disciplinary project PsyCris (PSYchosocial Support in CRISis Management), funded by the European Union with the overall objective to improve psycho-social support in crisis management.

Based on different impact models, the authors present the results of an assessment of different European major incidents. Data for assessment has been collected by conducting five case studies in Europe. The impact of these major incidents on health system performance, security and health protection has been investigated by using a questionnaire that was answered by the partners of the project based on articles, books, reports, films and photos. The literature-based questionnaire served as a foundation for a description of the basic facts and consequences of each disaster. It consisted of different topics and included questions concerning disaster management. Additionally, the collaborating partners interviewed key stakeholders who were involved in disaster/crisis management and civil protection. These interviews complemented the assessment.

Different indirect impacts of disasters on health system performance (e.g., changes and adaptions in medical, psychological or psychiatric treatment, psycho-
\end{abstract}


social support), security and health protection (e.g., optimisations in contingency/preparedness planning, infrastructure, training, increase in security research funding activities, information and communication measures) have been identified that might inspire other systems.

The analysis of the case studies has shown that each major incident has various indirect impacts on population health and health systems. Indirect effects identified are often the result of a learning process subsequent to a post-disaster analysis of inadequate management decisions and strategies or insufficient system performance.

Keywords: impact of major incidents, health system performance, security, health protection, psycho-social support.

\section{Introduction}

Disasters may have direct and indirect impacts on the population's health and healthcare system [1]. One aspect is the identification of direct health consequences such as deaths, injuries, psychological effects, and diverse diseases and illnesses [2]. Along with the population's health, the healthcare system itself can be affected by disasters due to damages and/or losses of personnel. The indirect consequences of disasters refer not only to losses of primary healthcare and living conditions and to limited or reduced access to administration, but also damages to healthcare systems regarding external infrastructure such as the provision of water and/or electricity [1]. Frederick et al. [2] have remarked that the indirect impact factors are very often not subject to planning or political attention and mostly remain undetected, unmeasured, and under-evaluated.

The diversity of impacts is enormous, which is shown by a number of different impact models trying to identify relevant impact variables [1, 3-9]. For example, Boyd et al. [10] clustered different categories: affected public, inter- and intraorganisational collaboration, preparing responders and their organisations, prioritisation and decision-making. The category "affected public" refers to recovery of the public, engagement of community groups and vulnerable populations, public risk communication or information and finally, the use of social networks. The category "inter- and intra-organisational collaboration" deals with collaboration across multiple organisations. A considerable number of healthcare and non-healthcare organisations are involved in prevention and recovery measures across public, private, and voluntary sectors. Large-scale incidents require collaboration across administrative boundaries in close coordination within brief time spans [11]. The category "preparing responders and their organisations" focuses on the learning and quality improvement in offering exercises and training measures for the people involved. Finally, the last category "prioritisation and decision-making" refers to the context, i.e. the social, administrative, and political context, in which the disaster occurred. This category refers to the priority and resourcing given to emergency planning and management, issues relating to organisational change as well as leadership and 
decision-making support systems during crisis are important pillars of this category [10]. The complexity and interdependencies make large-scale incidents particularly challenging.

Lindell [12] developed another framework for disaster management research that also considers social impacts (see Figure 1). Lindell's [12] concept of social impact consists of elements from the World Bank's report and is presented in an article by Lindell et al. [6]. It consists of three pre-impact conditions (exposure to hazard, physical vulnerability, social vulnerability) and three specific event conditions (hazard event characteristics, improvised disaster response, improvised disaster recovery). The hazard event characteristics and improvised disaster response, both parts of the event-specific conditions, in combination with the preimpact conditions produce the disaster's physical impacts that, together with recovery actions, consequently produce a disaster's social impacts.

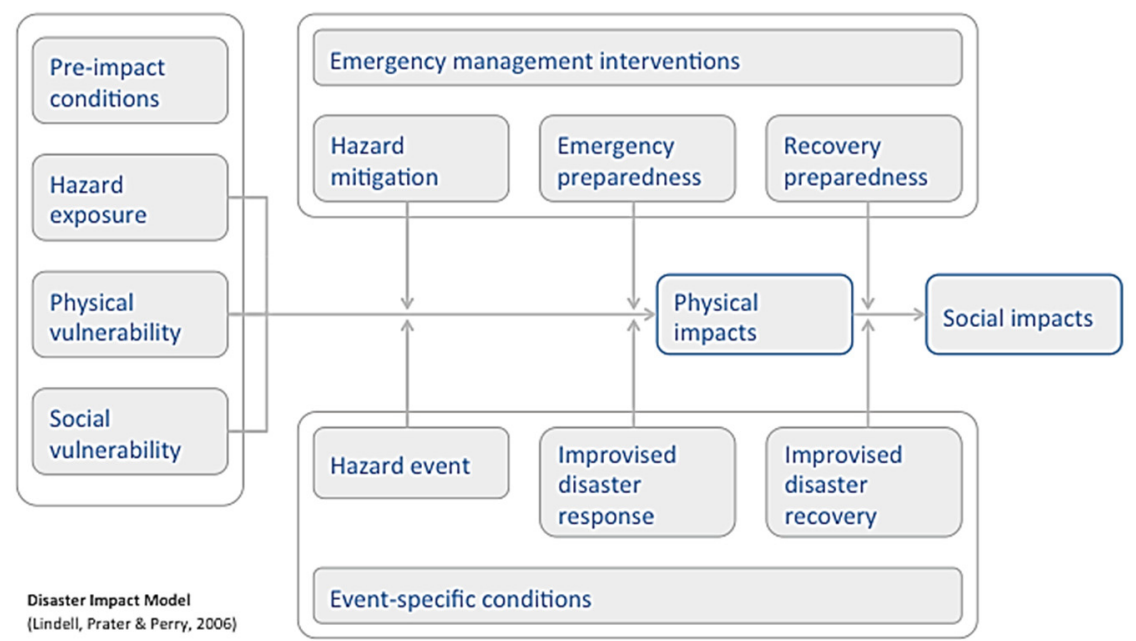

Figure 1: Disaster impacts (Lindell et al. [6]).

Lindell [12] has argued that communities can engage in different types of interventions to reduce a disaster's impacts. It is argued that hazard mitigation practices and emergency preparedness practices can reduce physical and social impacts.

This paper focuses on the direct health consequences of disasters and the indirect impacts of disasters on healthcare system performance, security and health protection measures. Health system performance usually refers to four basic functions such as financing, creating resources, stewardship and delivering services [13]. Security and health protection usually either refer to post-disaster efforts aiming at optimising contingency and preparedness planning, infrastructure and training or to an increase in security research funding activities as well as information and communication activities. 


\section{Methodology}

\subsection{Case study approach}

The decision for using a case study approach was made first to accommodate to the complexity of disasters. This research approach allows the representation of complexity and the specific circumstances of each disaster. Disasters, including their management, can be seen as a system consisting of different subsystems and functions. Everything is related, and nothing should be considered in isolation. As such, a holistic system-centred way of thinking is necessary [14].

Second, a case study approach allows the integration of a wide range of methods for analysis. We followed the World Bank report in integrating qualitative and quantitative information for impact analysis in order to better understand social phenomena [15, 16]. Joffe und Mindell [17] have also suggested the use of existing qualitative and quantitative data and studies for public health impact assessments, with the objective of combining them.

We built upon contrasting cases [18] since a variety of contexts, circumstantial factors, and their impact on each case could offer a more complete picture of impacts of crises on healthcare systems. For analysis, five specific cases from Spain, Lithuania, Luxembourg, Austria, and Germany were reconstructed to form the foundation for single case reports. Table 1 presents an overview of the chosen case studies.

\subsection{Questionnaire and expert interviews}

The literature and field research efforts produced a comprehensive register of benchmark data and textual material of key stakeholders. We put special focus on the development of a questionnaire as an exploratory tool for capturing both: various dimensions of crises in the European context and distinct crisis management responses. Based on the findings of a review, the questionnaire was developed as an exploratory tool for investigating and health assessing system effects. Apart from findings of our literature review, additional expert discussions and interviews with relevant stakeholders and endorsers supported us in identifying the central topics and problems. The questions in the questionnaire address different impacts of crisis on public healthcare. The main categories of the questionnaire are: General information about the chosen major incident, specific information concerning the chosen major incident, general coping strategies and direct effects on health, direct costs and follow-up costs (in $€$ ), long-term effects on the public healthcare system and long-term effects on culture and the community.

In a next step the research partners were asked to answer the listed questions in the questionnaire concerning their chosen major incident. They collected information (e.g., reports, studies, articles, books, films, photos) in order to answer the questions. Though the questionnaire was employed as a data gathering instrument of existing source material, the project partners were also asked to conduct interviews with at least three local stakeholders, who were involved in the 
disaster management of the chosen incident. The project partners interviewed experts from different fields like e.g. crisis managers (from several organisations), psychologists, forensics and politicians. This broad spectrum of different responsibilities helped us capturing the various aspects and issues of disasters. The interviewees provided first-hand data of the specific incident chosen, with the objective of identifying additional impact factors.

The analysis of the interviews applied the qualitative analysis method GABEKWinRelan (Holistic Coping with Complexity - GAnzheitliche BEwältigung von Komplexität), which supports the structuring of expressed experiences, knowledge, and perceptions of participants in order to provide a comprehensive view of the individual aspects of the particular situation investigated [19].

\section{Findings}

Our findings in each case study have then been grouped into three categories, based on the content of answers to the questionnaire as well as interviews conducted and in relation to consequences of each disaster: health system performance [13] (e.g., health diagnoses and demand for health care services), security and health protection (e.g., contingency and preparedness planning). First, we present in Table 1 an overview of the single case studies regarding number of affected people with focus on dead and injured people. Unfortunately, no or less detailed information and data has been provided about concrete injuries or further consequences for affected people, e.g. with regard to mental problems or diseases.

Table 1: Direct health impacts (dead and injured) of chosen disasters.

\begin{tabular}{|l|l|}
\hline \multicolumn{1}{|c|}{ Case } & Number of dead and injured \\
\hline Spain - Terror attack & 192 dead \\
& 1,857 injured \\
\hline Lithuania - (annual) Flood & $\begin{array}{l}\text { No information concerning dead/ } \\
\text { injured }\end{array}$ \\
\hline Luxembourg - Airplane crash & 20 dead \\
& 2 injured \\
\hline Austria - Avalanche & 31 dead \\
& 22 injured \\
\hline Germany - School shooting & 17 dead \\
& 6 injured \\
\hline
\end{tabular}

In the next step, we present the main results with regard to indirect impacts on health care systems, security and health protection with focus on psycho-social support (Figures 2 and 3). We will also explain shortly the most important impact(s) we identified, based on the data of the questionnaire and interviews for each case. We start with Austria, followed by Luxembourg, Lithuania, Spain and Germany. 
1116 Sustainable Development, Vol. 2
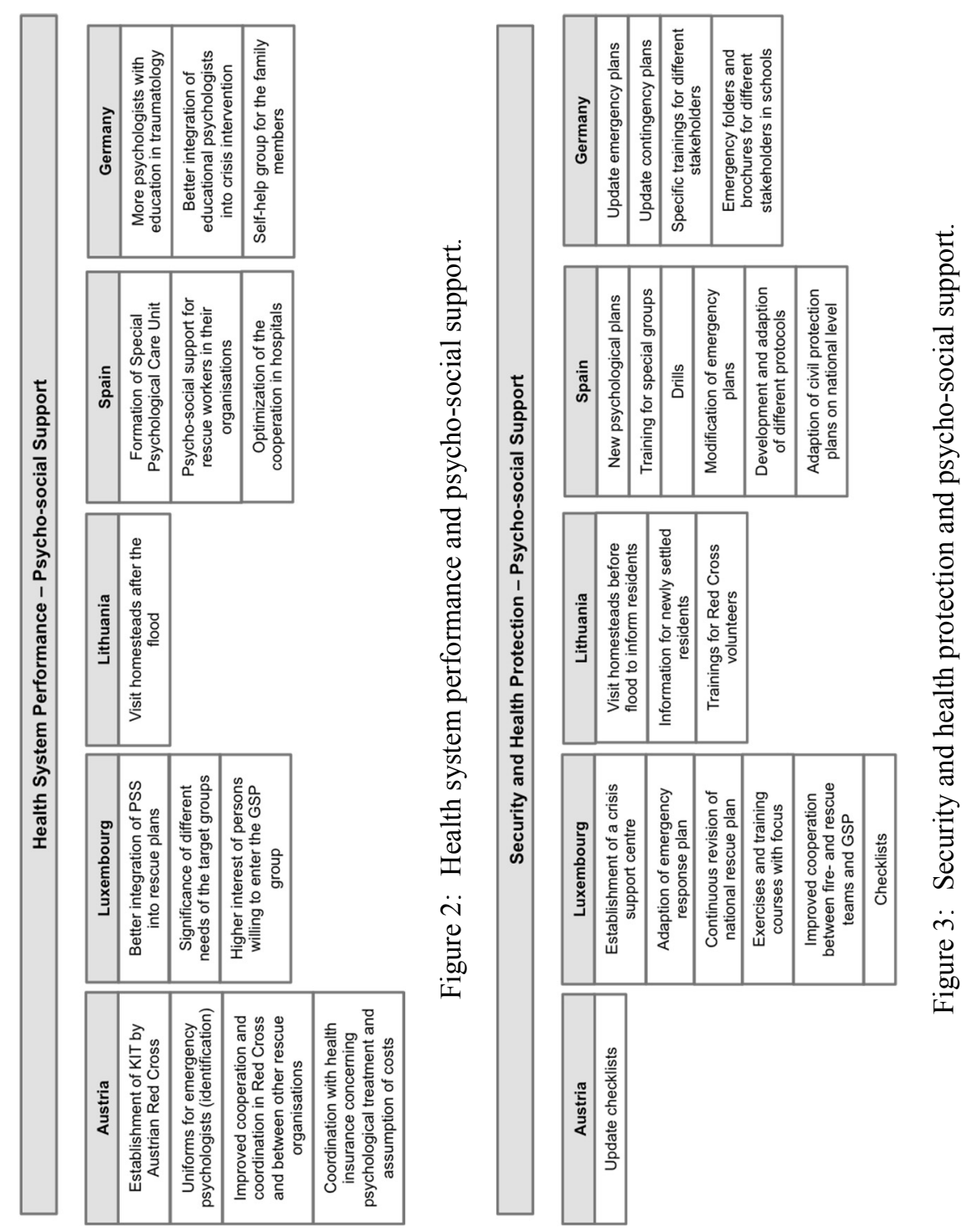
Because of the - at that time - neither institutionalised nor interorganisationally coordinated provision of psycho-social support during the avalanche disaster in Austria, the establishment of the Austrian crisis intervention team in close cooperation with the Austrian Red Cross is one of the most relevant impacts in the context of health system performance.

As result of the airplane crash in Luxembourg we identified a number of new formations of units, committees, teams and centres. As also identified in the other case studies, the revision of emergency plans, national rescue plans or national hospital plans have been realised. The structure of psycho-social support itself has not changed. One learning experience was to adapt more on the individual needs of affected people.

Lithuania is confronted on a regular basis with natural disasters, since there are annual river floods due to snow and ice melting activities as well as periods of long-lasting rain. In this context, visits before the floods, especially in the case of newly settled residents, are organized. Guidelines for the behaviour in the case of floods as well as operation plans for vulnerable groups have been developed and adapted regularly. Additional trainings are offered for Red Cross volunteers and for pupils in schools. For psycho-social support supply visits after the flood have been organized to check the living and health conditions of residents.

As in the other case studies, also in Spain a number of plans (e.g., emergency plans, civil protection plans) were developed or adapted after the attack by representatives of the involved emergency organisations. Additionally, training measures and drills for special groups were organized with the objective to improve processes as well as co-operations between rescue teams, authorities etc. In the context of psycho-social support the extent of the event has led to the formation of a special psychological care unit which takes over the organisation and management of psycho-social support in case of disasters. Due to the major impact of the terror attack, a systemized supply of psycho-social support for rescue workers in their organisations has been established. After the terror attack, the improvement of cooperation and collaboration between staff members in hospitals, but also between staff members and psychologists became explicit.

After the school shooting in Germany, an important impact with focus on health system performance of the concerned federal state mainly refers to changes in training requirements of psychologists involved in psycho-social support. They now have to dispose of knowledge and training in traumatology. Additionally, a better integration of educational psychologists is seen as relevant backup for crisis intervention on-site. In the case of the school shooting, a self-help group of family members has been organised to provide support in dealing with the incident.

\section{Discussion}

The analysis of the case studies has shown that each disaster causes aftermaths in different fields. During our analysis we experienced that learning circles play a significant role in the context of crisis preparedness and management. Many impacts on health care systems identified are the result of a learning process driven by the experiences of inadequate support and supply in the past. Moreover, most 
of the impacts identified in the different case studies are the result of each disasters' collected experiences and reflective analysis of operations and results (e.g., which implications can be drawn because of operations that lead to the adaption of emergency plans, communication structures, laws, infrastructure, etc.). As the detailed analysis of each case study has shown, new structural, procedural and legal concepts have been developed and implemented in different sector of the health systems affected.

Each disaster is characterized by event specific conditions, pre-impact conditions, the existing physical or social vulnerability of affected people and the standard of the emergency system. However, different recovery needs have been identified and stressed depending on different dimensions and contexts of the analysed disasters as well as on different system conditions.

During our case study analysis we were confronted with different problems, mostly referring to non-existing or missing post-disaster information. Almost no reliable quantitative data was available, thus. Responses to questionnaires were not comprehensive. Some databases are not always valuable resources, additional personal contacts and expert knowledge was needed to provide further reliable information. We were also confronted with the problem of judging the quality of evidence from different sources.

Finally, there have been several problems regarding ex-post analysis, because of concealments, glorification, objectifications of decision makers' actions, or problems of political exploitations.

We share the recommendation expressed by Verger et al. [20] declaring a need for systematic and cross-linked health evaluation programmes after disasters to allow more thorough impact analyses. This must be designed holistically in order to measure direct physical and mental health effects, as well as indirect health effects like job loss, schooling consequences, etc. in order to identify the multilayer impacts of disasters. For example, alcohol abuse - caused by inadequate coping strategies of an individual after a disaster - may cause an inability to work. There is a need for more qualitative analysis of case studies that may support the process to identify further impacts of disasters. For high quality analysis of long-term impacts, we need decision-making support, public information, and scientific knowledge. In addition, an intensive collaboration between politicians, authorities and research institutions to manage programme evaluations in European countries is needed [20].

Although each disaster is unique in its progress and coping, we ask for the design of a uniform measurement system for specific questions of interest. Additionally, for the comparison of similar disasters the data reliability and validity can be facilitated. Because of the multiple dimensions that must be taken into consideration for a measurement system, we demand the participation of multiple stakeholders from different disciplines. We also suggest an information platform with the objective to provide the results (e.g., programme success, case study analysis) for other European countries to share the experienced data. The success of such a platform depends on how the information processing of the result is done. The information must be designed in an intelligent form to support stakeholders in their decision process. 


\section{Summary}

The case study analysis focusing on impacts of disasters using a questionnaire approach in combination with interviews with relevant system stakeholders provided us insights into a disaster's effects on the health system with special focus on health system performance as well as security and health protection.

We have identified many impact variables in conjunction with different time frames. The impact variables and time frames depend on the nature and extent of the disaster, affected people, existing infrastructure etc. The attribution of impacts to the categories "health system performance" and "security and health protection" has been proved as reasonable and gave a first systematisation of direct and indirect impacts.

Our chosen holistic approach gave us deep insights into each case study and helped us to better understand the undertaken reactions concerning health care systems. Based on the learning experiences of the case studies we are able to evaluate key strategies and measures from a health care system perspective.

\section{Acknowledgements}

We thank all crisis managers and other stakeholders who shared their experiences with us, who gave us feedback during these initial steps and helped us develop the current concept. We would also like to thank all our project partners for their tireless support during the past months to finally reach this point, where we can start to discuss our current research.

This project has received funding from the European Union's Seventh Framework Programme for research, technological development and demonstration under grant agreement no 312395.

\section{References}

[1] Shoaf, K. I., \& Rottman, S. J., Public health impact of disasters. Australian Journal of Emergency Management, 15(3), pp. 58-63, 2000.

[2] Frederick, M., Burkle, Jr., Greenough, G., Impact of Public Health Emergencies on Modern Disaster Taxonomy, Planning, and Response. Disaster Medicine and Public Health Preparedness. Vol. 2 No. 4, pp. 2-9, 2008.

[3] Berggren, R.E:, Curiel, T.J., After the storm - health care infrastructure in post-Katrina New Orleans. New England Journal of Medicine, 354, pp. 1549-1552, 2006.

[4] Donker, G. A., Yzermans, C. J., Spreeuwenberg, P., Van der Zee, J., Symptom attribution after a plane crash: comparison between self-reported symptoms and GP records. British Journal of General Practice, 52, pp. 917922, 2002.

[5] Ferrando, L., Galea, S., Sainz Cortón, E., Mingote, C., García Camba, E., Fernandez Líria, A. \& Gabriel, R., Long-term psychopathology changes 
among the injured and members of the community after a massive terrorist attack. European Psychiatry, 26, pp. 513-517, 2011.

[6] Lindell M.K, Prater C.S, Perry R.W., Fundamentals of Emergency Management, Emmitsburg, MD: Federal Emergency Management Agency Emergency Management Institute. Available at www.training.fema.gov/EMIWeb/edu/fem.asporarchone.tamu.edu/hrrc/ Publications/books/index.html

[7] Roorda, J., Van Stiphout, W. A. H. J., Huijsman-Rubingh, R. R. R.,. Postdisaster health effects: strategies for investigation and data collection. Experiences from the Enschede firework disaster. Journal of Epidemiology and Community health, 58, pp. 982-987, 2004.

[8] Tunstall, S., Tapsell, S., Green, C., Floyd, P., George, C., The health effects of flooding: social research results from England and Wales. Journal of Water and Health, 4, pp. 365-380, 2006.

[9] Zaetta, C., Santonastaso, P., \& Favaro, A., Long-term physical and psychological effects of the Vajont disaster. European Journal of Psychotraumatology, 2, 2011.

[10] Boyd, A., Chambers, N., French, S., King, R.A., Shaw, D., Whitehead, A.S., A scoping study of emergency planning and management in health care: What further research is needed? Final report. NIHR Health Services and Delivery Research programme, 2012.

[11] Boyd, A., Chambers, N., French, S., Shaw, D., King, R., Whitehead, A., Emergency planning and management in health care: priority research topics. Health Systems, 3, pp. 83-92, 2014.

[12] Lindell, M.K., Disaster studies. Lindell, M.K., 'Disaster studies', Sociopedia: http://www.isa-sociology.org/publ/sociopedia-isa/sociopediaisa-list-of-published-entries.htm

[13] Murray C, Evans D (Eds.), Health Systems Performance Assessment, Debates, Methods and Empiricism, WHO, Geneva, available at: whqlibdoc.who.int/publications/2003/9241562455.pdf?ua=

[14] Gummesson, E., Qualitative research in management: addressing complexity, context and persona. Management Decision, 44(2), pp. 167179, 2006.

[15] World Bank, Analyzing the Social Impacts of Disasters, Volume I: Methodology, Retrieved September 8, 2014 from:

http://siteresources.worldbank.org/INTEAPREGTOPSOCDEV/Resources /PostDisasterocialAnalysisToolsVolumeI.pdf

[16] World Bank, Analyzing the Social Impacts of Disasters, Volume II: Tools Retrieved September 8, 2014 from:

http://siteresources.worldbank.org/INTEAPREGTOPSOCDEV/Resources /PostDisasterSocialAnalysisToolsVolumeII.pdf

[17] Joffe, M., \& Mindell, J., A framework for the evidence base to support Health Impact Assessment. Journal of Epidemiology and Community Health, 56(2), 132-138, 2002.

[18] Mabry, L., Case study in social research. The Sage handbook of social research methods. SAGE Publications: London, 2008. 
[19] Zelger J., Serielle und parallele Wissensverarbeitung. Die Simulation von Gesprächen durch GABEK. In R. Buber \& J. Zelger (Eds.), GABEK II Studienverlag: Innsbruck u.a., pp. 31-91, 2000.

[20] Verger, P., Aulagnier, M., Schwoebel, V., Lang, Th., French experiences with Health Impact Assessment of disasters, European Journal of Public Health, Vol. 17, No. 1, pp. 3-7, 2006. 